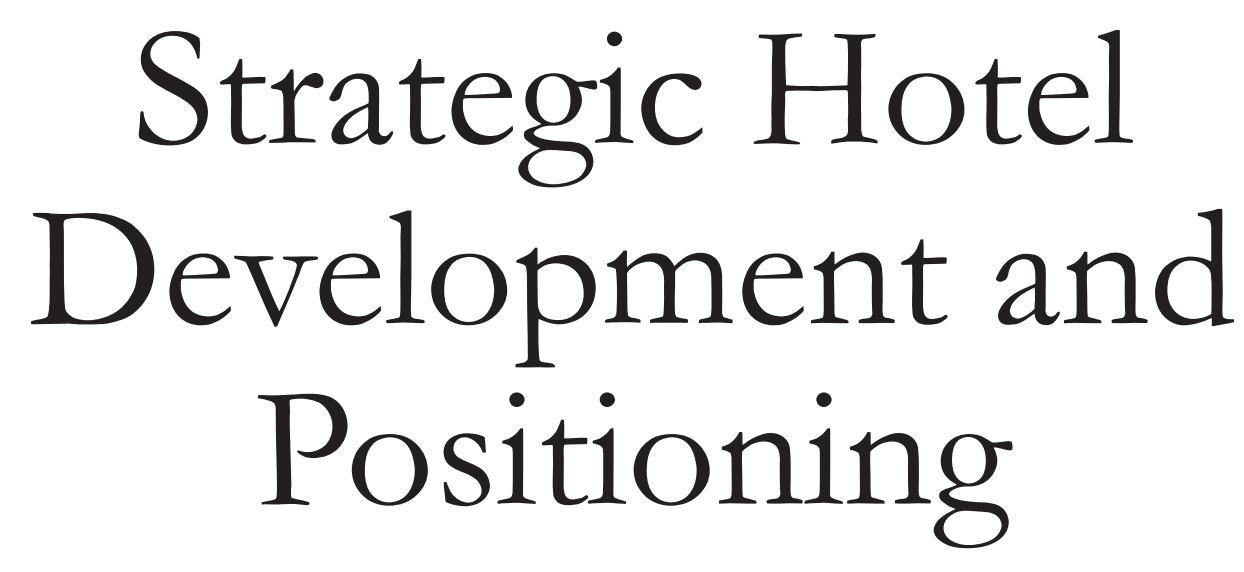

The Effects of Revenue Drivers on Profitability

by JOHN W. O'NEILL and ANNA S. MATTILA

A study of more than nineteen hundred U.S. hotels for the years 2002 and 2003 found that a hotel's net operating income percentage is most closely tied to its occupancy, although average daily rate (ADR) has a strong influence, as does market segment (also known as chain scale), the age of the property, and brand affiliation. A hotel's size (that is, number of rooms) and location (e.g., urban or highway) also influence net operating income (NOI), but a hotel's region does not significantly affect NOI percentage. The year 2002 data particularly show the importance of heads in beds. Hoteliers cut ADR heavily in that recession year, and those hotels that maintained strong occupancy were the ones that enjoyed strong NOI. While resorts and urban hotels generated the highest $\mathrm{NOI}$ in raw dollar volume, economy hotels had the highest $\mathrm{NOI}$ percentage and midscale hotels with food and beverage service $(F \& B)$ had the lowest $\mathrm{NOI}$ percentage.

Keywords: hotel profitability; net operating income; RevPAR

\footnotetext{
s hotel management and development organizations formulate strategies and programs regarding existing and future hotel facilities, services, and positioning, a question that naturally arises is, What actually drives a hotel's profitability? Should a developer be building a hotel that will command a huge average daily rate, or is a hotel that fills up every night the one that will have the highest net income levels? Along that line, do different types or scales of hotels have different net income levels, or is
} 
net operating income (NOI) a function of location or some other factor? In other words, do different types of hotels possess naturally different levels of profitability, and how should occupancy and average daily rate ideally be positioned for any existing or proposed hotel?

It only makes sense that hotel operators and developers would favor more profitable concepts over less profitable ones, as suggested by the recent trend toward the development of limited-service midscale hotels (that is, those without food and beverage $[\mathrm{F} \& \mathrm{~B}]) .{ }^{1}$ Though the profitability goal of hotels is fairly clear, there exists a significant level of "noise" in the hotel industry regarding the actual relationship between hotel revenue indicators, including occupancy percentage and average daily rate, and profitability.

In our research, we attempt to compare the effects of high occupancy with those of average daily rate maximization on hotels' overall net operating income and on their NOI percentage. Through this article, we hope to begin to cut through some of the noise regarding hotel revenue and profitability relationships. Specifically, while controlling for such variables as hotel age, brand, scale (that is, market segment), and location, we seek to reveal which types of hotels are most profitable. In so doing, we hope to assist hotel owners, operators, and developers with the decision-making processes of hotel development, positioning, and repositioning.

In addition to bottom-line financial ratios, top-line financial indicators, such as average daily rate (ADR) and revenue per available room (RevPAR), are valuable tools for hospitality executives and managers. Although we could argue that financial executives are strongly bottomline focused, they also pay close attention to revenue maximization, as indicated by the industry's fascination with ADR and
RevPAR. In fact, these two ratios were ranked as the two most crucial operating indicators by lodging executives in one recent study, ${ }^{2}$ and another recent study found that a hotel's ADR is a better predictor of a hotel's value than its NOI. ${ }^{3}$ The conclusion of both studies was that there is not only a relationship between a hotel's top line and bottom line but that operators believe a hotel's top line is an indicator of its potential as much as its actual bottom line.

Although occupancy, ADR, and RevPAR should explain a large amount of the variation in a hotel's bottom line, the age of the hotel, the type of hotel, and its brand affiliation are additional important factors potentially affecting its bottom line. The branding literature has demonstrated that consumers use brand name as an important quality cue. ${ }^{4}$ Moreover, consumers are typically willing to pay a price premium for brands they view as high in quality. ${ }^{5}$ Similarly, previous research suggests that hotel size (that is, number of rooms) influences profitability. ${ }^{6}$ Finally, property type is likely to influence the hotel's bottom line. ${ }^{7}$ For example, limitedservice hotels have been shown to be more profitable than full-service operations with F\&B.

\section{What We Did}

To better understand the relationships between a hotel's top line and bottom line, we used data graciously provided to us by Smith Travel Research (STR). Specifically, STR provided occupancy percentage, ADR, and NOI for 2002 and 2003 for a total of 1,954 hotels operating in the United States. All of these data were available for the same two consecutive twelvemonth annual time periods for these hotels. In addition, for each hotel, STR provided the hotel's scale, location type, region, and number of rooms. Characteris- 
Exhibit 1:

Hotel Sample Characteristics, 2003

\begin{tabular}{|c|c|c|c|c|}
\hline Characteristic & Mean & Minimum & Maximum & $\begin{array}{l}\text { Standard } \\
\text { Deviation }\end{array}$ \\
\hline Number of rooms & 236 & 15 & 2,860 & 223 \\
\hline Occupancy & $66.7 \%$ & $23.5 \%$ & $97.3 \%$ & $10.5 \%$ \\
\hline $\begin{array}{l}\text { Average daily rate } \\
\text { (ADR) }\end{array}$ & $\$ 93.82$ & $\$ 27.95$ & $\$ 577.06$ & $\$ 43.15$ \\
\hline $\begin{array}{l}\text { Revenue per available } \\
\text { room (RevPAR) }\end{array}$ & $\$ 62.77$ & $\$ 12.42$ & $\$ 341.37$ & $\$ 31.46$ \\
\hline Room revenues & $\$ 6,536,711$ & $\$ 363,919$ & $\$ 131,371,602$ & $\$ 10,622,372$ \\
\hline Total revenues & $\$ 9,789,960$ & $\$ 385,751$ & $\$ 215,894,640$ & $\$ 17,904,046$ \\
\hline $\begin{array}{l}\text { Net operating income } \\
\text { (NOI) }\end{array}$ & $\$ 1,705,280$ & $(\$ 11,273,498)$ & $\$ 57,273,088$ & $\$ 4,190,383$ \\
\hline NOI percentage & $19.2 \%$ & (85.3\%) & $87.5 \%$ & $20.6 \%$ \\
\hline
\end{tabular}

tics of this sample of hotels are presented in Exhibit 1 (means, minimums, and maximums), Exhibit 2 (frequencies), and Exhibit 3 (correlation coefficients).

NOI percentage. Hierarchical regression analyses were used to test the effects of RevPAR (divided into ADR and occupancy) on NOI percentage while taking into consideration the effects of the brand, location, region, property age, location type, and scale. A two-step procedure was used in which the control variables were entered in the first step followed by the two performance-indicator variables (that is, occupancy percentage and ADR). The regression results are shown in Exhibit 4.

Exhibit 4 indicates that both occupancy percentage and ADR account for a significant increase in $R$-squared, ${ }^{8}$ indicating that these variables explain a significant amount of the variation in NOI percentage beyond that explained by the control variables of brand, location, region, property age, location type, and scale. As expected, both occupancy and ADR are positively linked to NOI percentage.' However, occupancy seems to be a better predictor of NOI percentage than is ADR. As our results indicate, being one standard deviation better than your competitors at ADR is worth a .08 point increase in NOI percentage, while being one standard deviation higher in occupancy results in a .34 point increase in NOI percentage.

In addition to occupancy and ADR, scale, property age, and brand affiliation are significant predictors of NOI percentage. Conversely, number of rooms, location type, and region fail to explain variation in NOI. Property age and brand affiliation are also positively linked to the bottom line. Since we do not have access to brand names, it is not possible for us to discern the effects of individual brands on NOI percentage, other than to indicate that brand matters. In the data provided to us by STR, each individual hotel property's brand was represented by a specific number. In other words, while we were not provided with each of the individual brand names, we knew which hotels were affiliated with a common brand, and some brands had stronger bottom lines than others did. 


\section{Exhibit 2:}

Hotel Sample Frequencies $(N=1,954)$

\begin{tabular}{lr}
\hline Scale & \\
Luxury chains & $2.4 \%$ \\
Upper upscale chains & $29.7 \%$ \\
Upscale chains & $31.2 \%$ \\
Midscale with food and & $8.2 \%$ \\
$\quad$ beverage (F\&B) chains & \\
Midscale without & $15.4 \%$ \\
$\quad$ F\&B chains & \\
Economy chains & $8.6 \%$ \\
Independents & $4.5 \%$ \\
Location type & \\
Urban & $16.7 \%$ \\
Suburban & $39.7 \%$ \\
Airport & $18.9 \%$ \\
Highway & $18.0 \%$ \\
Resort & $6.7 \%$ \\
Region & \\
New England & $5.3 \%$ \\
Middle Atlantic & $9.2 \%$ \\
South Atlantic & $26.5 \%$ \\
East North Central & $12.2 \%$ \\
East South Central & $5.8 \%$ \\
West North Central & $5.3 \%$ \\
West South Central & $11.8 \%$ \\
Mountain & $8.1 \%$ \\
Pacific & $15.4 \%$ \\
All suite & $38.0 \%$ \\
Not all suite & $62.0 \%$ \\
Extended stay & $21.5 \%$ \\
Not extended stay & $78.5 \%$ \\
One or more restaurants & $60.1 \%$ \\
No restaurants & $39.9 \%$ \\
& \\
\hline & \\
\hline & \\
& \\
\hline
\end{tabular}

To gain further insight into the scale effects, we examined how NOI percentages vary depending on the hotel type. The mean values are shown in Exhibit 5. As shown in that table, economy chains have the highest mean NOI percentage (39.1 percent) while midscale hotels with $\mathrm{F} \& \mathrm{~B}$ operations are the least profitable (6.7 percent).

To examine the robustness of our regression model, we ran the analyses with 2002 data as well. As with 2003 data, property occupancy, age, scale, and brand affiliation were significant predictors of NOI percentage. Interestingly, ADR was only marginally significant. It thus seems that in the U.S. hotel industry in 2002, following the 9/11 attacks, ADR was a less significant factor in driving hotels' bottom lines than was occupancy.

NOI volume. Finally, we examined the relationship between top lines and bottom lines by using actual NOI as a dependent variable, as opposed to NOI percentage. The regression results for 2003 data indicate that ADR and occupancy and all control variables except for region are important determinants of NOI. Specifically, hotels with higher occupancies and ADRs have higher NOIs, with each additional point in occupancy resulting in an additional $\$ 69,826$ in NOI, and each additional dollar in ADR resulting in an additional $\$ 17,275$ in NOI. As one would expect, property size has a positive effect on the NOI line. Moreover, location type also influences the bottom line. Specifically, resort hotels (with an average NOI of $\$ 5,431,186$ ) and urban hotels (with an average NOI of $\$ 3,478,463)$ are significantly more profitable in terms of NOI than airport hotels (with average NOI of $\$ 1,126,519$ ), suburban hotels (averaging $\$ 995,532)$, and highway hotels (at $\$ 847,030)$.

\section{Discussion}

The findings of this study shed light on the relationship between specific operating factors and a hotel's bottom line. Occupancy, brand affiliation, age of the property, and scale are directly linked to NOI percentage in both 2002 and 2003 data. In contrast, the impact of ADR seems to depend on the state of the economy. Under normal operating conditions, 


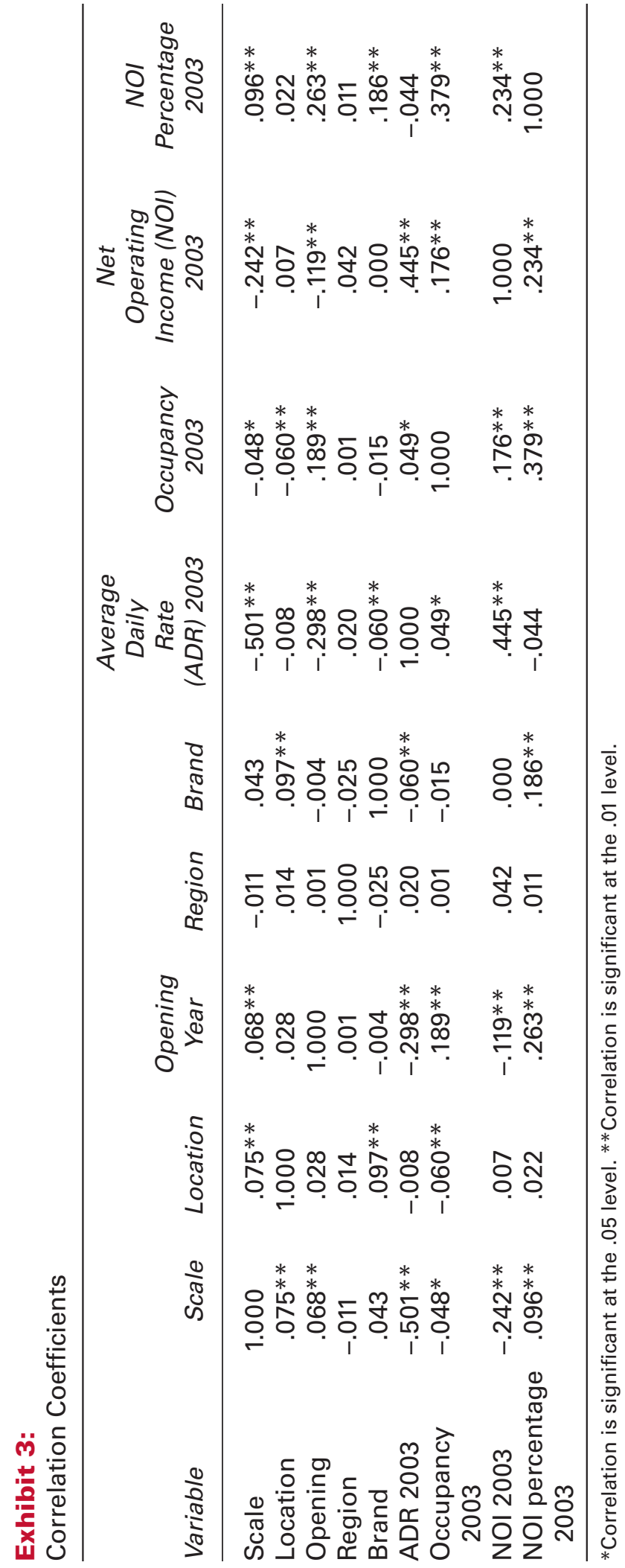


Exhibit 4:

Regression Results

\begin{tabular}{|c|c|c|c|c|}
\hline & \multicolumn{2}{|c|}{$\begin{array}{c}\text { Standardized Beta } \\
\text { Coefficient }\end{array}$} & \multicolumn{2}{|c|}{ t-Value } \\
\hline & $\begin{array}{c}\text { Net Operating } \\
\text { Income (NOI) } \\
\text { Percentage }\end{array}$ & NOI (\$) & $\begin{array}{c}\text { NOI } \\
\text { Percentage }\end{array}$ & $\mathrm{NOI}(\$)$ \\
\hline \multicolumn{5}{|l|}{ Step 1} \\
\hline Number of rooms & .023 & .821 & .93 & $49.56 *$ \\
\hline Scale & .085 & .068 & $3.61 *$ & $4.30 *$ \\
\hline Age & .265 & .104 & $11.80 *$ & $6.86^{*}$ \\
\hline Location & -.007 & .064 & -.32 & $4.35 *$ \\
\hline Region & .013 & -.01 & .59 & -.65 \\
\hline Brand & .185 & .036 & $8.57^{*}$ & $2.45^{*}$ \\
\hline Adjusted $R$-squared & .108 & .591 & & \\
\hline \multicolumn{5}{|l|}{ Step 2} \\
\hline Number of rooms & -.003 & .770 & -.13 & $47.62^{*}$ \\
\hline Scale & .131 & .144 & $5.47^{*}$ & $8.87 *$ \\
\hline Age & .213 & .105 & $9.70^{*}$ & $7.04 *$ \\
\hline Location & .010 & .065 & .48 & $4.71 *$ \\
\hline Region & .013 & -.01 & .63 & .48 \\
\hline Brand & .190 & .043 & $9.43^{*}$ & $3.13 *$ \\
\hline Average daily rate (ADR) & .079 & .177 & $3.08 *$ & $10.19 *$ \\
\hline Occupancy & .343 & .174 & $16.70^{*}$ & $12.44 *$ \\
\hline Adjusted $R$-squared & .228 & .643 & & \\
\hline
\end{tabular}

*Regression is significant at the .05 level.

such as during 2003, higher ADR clearly contributes to the bottom line. But in 2002, the relationship between ADR and profitability was marginal. This weak link following the 9/11 events can be best understood in light of heavy discounting during 2002. The battle for guests led to an industry-wide price war, which in turn enabled guests to trade up and stay at more upscale properties for the price they would have paid for lower-tier hotels. As a result, rate differentiation became less important than usual in driving consumer choices.

In addition to ADR and occupancy, our results indicate that profitability is also driven by hotel type. As far as NOI percentage is concerned, the most profitable type of hotel in our study is the economy hotel type (39.1 percent mean NOI), while midscale hotels with $\mathrm{F} \& \mathrm{~B}$ are the least profitable type (with a mean NOI of 6.7 percent). In terms of NOI expressed in dollar volume, rather than percentage, resort and urban hotels seem to generate the highest bottom-line results. These results are not surprising given the captive nature of most resort operations. Similarly, the demand for many urban hotels tends to be relatively high, thus driving up their rate structures.

As one would expect, new properties tend to be more profitable than old hotels. In addition to increased maintenance costs, old properties can lose their com- 
Exhibit 5:

Mean Net Operating Income (NOI) by Hotel Scale, 2003

\begin{tabular}{lrc}
\hline Scale & $N$ & Mean NOI Percentage \\
\hline Luxury chains & 47 & 9.1 \\
Upper upscale chains & 581 & 13.6 \\
Upscale chains & 610 & 27.1 \\
Midscale with food and beverage (F\&B) & 160 & 6.7 \\
Midscale without F\&B chains & 300 & 13.5 \\
Economy chains & 169 & 39.1 \\
Independents & 87 & 10.7 \\
Entire sample & 1,954 & 19.2 \\
\hline
\end{tabular}

petitive edge due to functional obsolescence (if they are not continually updated), thus having a "doublewhammy" effect on profitability.

Overall, our findings suggest that all other things being equal, hotel properties with higher occupancy and ADR (that is, higher RevPAR) are more profitable properties, with higher NOI percentage. However, we contend that dollars are what count in the final analysis, so we conclude that the most profitable hotel business model is one that generates the greatest room revenue. To the extent that food, beverage, or ancillary facilities generate additional room revenue (not merely additional total revenue), through the attraction and accommodation of new, additional segments of lodging demand, such as groups desiring these ancillary facilities, it supports this profitable business model.

Our findings provide additional support for the power of branding in influencing a hotel's bottom line (even though we had no way of knowing which brand was which). This finding is consistent with the notion that well-established brands create financial value due to their ability to generate cash flows via relatively higher margins. ${ }^{10}$ Given the strong link between brand equity and financial results, it is not surprising that previous research on the lodging industry found significant variation among U.S. hotel brands, not only in occupancy, ADR, and RevPAR, but also in annual growth in RevPAR. ${ }^{11}$ Yet it is clear that hotel companies differ in their choice of branding strategies, so that potential franchisees need to examine the parent firm's brand portfolio.

It is worth noting that we found significant variation in profitability by brand because prior research in marketing suggests that the brand's contribution to the bottom line might depend on the parent firm's branding strategy. ${ }^{12}$ Some companies, such as Marriott, include the corporate name in most of their brands, while others (e.g., Cendant) employ a house-ofbrands strategy (i.e., individual brand names for each segment). Although this research does not allow us to derive specific recommendations about the effects of the parent company's branding strategy on the hotel's bottom line (or to reveal individual brand names), we believe that examining such effects in future studies would be highly beneficial to both hotel owners and franchisors.

Brand hopping, or "flag switching," among hotel owners and developers has 
become a concern among hotel franchisors over the past few years. ${ }^{13}$ Our data indicate that this concern is well placed, because it became clear in our study that different hotel brands deliver different levels of profitability. Hotel owners have figured this out, based on their prior brand relationships, and they have become less hesitant to seek brands that are in closer conformance to their financial goals. To assist such hotel owners and developers who are trying to match up with the business model best for them, we hope to have clarified some of the "noise" that exists in the hotel brand marketplace about the relationships between hotel top and bottom lines, using the best available statistical evidence.

In sum, we conclude that across our large sample of different hotel properties, occupancy is ultimately a larger contributor to a hotel's bottom line than is ADR, particularly under recessionary conditions. All other factors being equal, hotels with higher occupancies (i.e., "heads in beds") are more profitable. This conclusion does not support a frequently stated belief in the hotel industry that hotels with relatively higher ADRs and relatively lower occupancies are more profitable because their costs are relatively lower. Our research indicates that hotels with higher occupancy may in fact trade some ADR for greater efficiencies, allowing them to be more profitable.

Since the link between occupancy and NOI appears to be strongest during periods of general recession in the hotel business, such as 2002, it suggests that it was probably a wise strategic decision for hoteliers to sacrifice some ADR to gain occupancy during that soft demand period. Far from being a destructive strategy, consumers gained relatively lower room rates while operators enjoyed the maximum profitability that the economic situation would allow. As the economy improves and hoteliers experience less room-rate resistance, there is a great tendency to rapidly increase room rates. However, this research indicates it is vital for operators to always maximize occupancy percentage.

\section{Endnotes}

1. J. W. O'Neill, "ADR Rule of Thumb: Validity and Suggestions for Its Application," Cornell Hotel and Restaurant Administration Quarterly 44, no. 3 (August 2003): 7-16.

2. A. Singh and R. Schmidgall, "Analysis of Financial Ratios Commonly Used by Lodging Financial Executives," Journal of Leisure Property 2, no. 3 (August 2002): 201-13.

3. O'Neill, "ADR Rule of Thumb."

4. See J. Jacoby, G. Szybillo, and J. BusatoSchach, "Information Acquisition Behavior in Brand Choice Situations," Journal of Consumer Research 3, no. 4 (1977): 209-17; and M. Brucks, V. Zeithaml, and G. Naylor, "Price and Brand Name as Indicators of Quality Dimensions for Consumer Durables," Journal of the Academy of Marketing Science 28 (summer 2000): 359-75.

5. See M. Johnson and F. Selnes, "Customer Portfolio Management: Toward a Dynamic Theory of Exchange Relationships," Journal of Marketing 68, no. 2 (2004): 1-19; and R. Bolton, K. Lemon, and P. Verhoef, "The Theoretical Underpinnings of Customer Asset Management," Journal of the Academy of Marketing Science 32, no. 3 (2004): 271-93.

6. G. Withiam, "Size Matters," Cornell Hotel and Restaurant Administration Quarterly 41, no. 5 (October 2000): 15.

7. A. Singh and R. Schmidgall, "Financing Lodging Properties," Cornell Hotel and Restaurant Administration Quarterly 41, no. 3 (August 2000): 39-47.

8. Change in $R^{2}=.143, F(2,1544)=135.43, p<$ .001 .

9. $t=16.33, p<.001$.

10. D. Aaker and R. Jacobson, "The Financial Information Content of Perceived Quality," Journal of Marketing Research 31 (May): 191201.

11. J. W. O'Neill and A. S. Mattila, "Hotel Branding Strategy: Its Relationship to Guest Satisfaction and Room Revenue," Journal of Hospi- 
tality \& Tourism Research 28, no. 2 (May 2004): 156-65.

12. V. Rao, M. Agarwal, and D. Dalhoff, "How Is Manifest Branding Strategy Related to the In- tangible Value of a Corporation?" Journal of Marketing 68, no. 4 (2004): 126-41.

13. The Wall Street Journal, May 20,2002, p. B11.
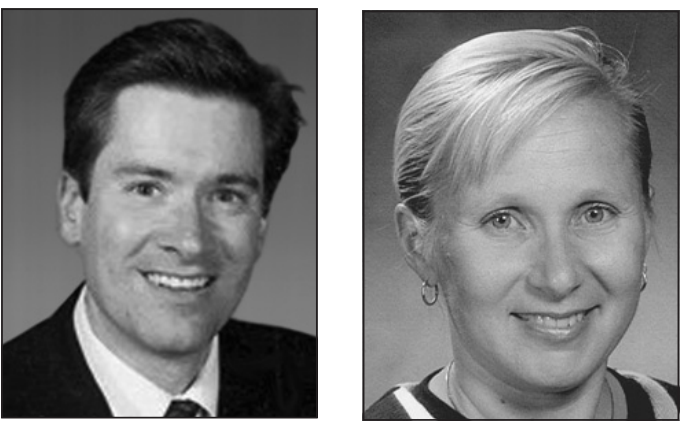

John W. O'Neill, Ph.D., is an assistant professor at The Pennsylvania State University (jwo3@psu.edu), where Anna S. Mattila, Ph.D., is an associate professor1asm6@psu .edu). The authors gratefully acknowledge the assistance of Mark V. Lomanno, president of Smith Travel Research. 